\title{
Essential
}

\section{Community Medicine}

(including relevant social services)

‘. f full marks for being up to date. ... I would congratulate the Donaldsons. Their work will serve both medical students and trainees in community medicine well, especially if it is used as a core book. It is good value.'

British Medical Journal

'...there are. .. few useful reference books which describe the pattern of problems and the pattern of services as carefully and clearly as this one does.'

\section{Lancet}

'This is an extremely interesting and useful book. I know of no other that brings together all the strands of community health, in a style that everyone from a member of a regional health authority to the consumer can understand and enjoy ... deserves a place on the bookshelves of local clinics and surgeries as well as schools of nursing libraries.'

Nursing Times

'... essential reading for students of medicine, nursing, public health and social work. ... for a book running to almost 600 pages it has to be one of the best buys in its field.'

Royal Society of Health Journal

'... likely to become the definitive work in Community Medicine. The book is well produced; the writing style is clear, there has been great attention to accuracy and complex matters are explained simply and well, there are a large number of good illustrations and helpful tables.'

Medical Record

'I like this book. It is amazingly good value, the production is pleasing and it is pleasant to handle. ... recommended to general practitioners and hospital doctors as a source book on epidemiological facts, and information on the structure and workings of the NHS. . . . it is a bargain.'

Update

'This book is never dull - the text is basic, concise, clear and factual and well tabulated. Intriguing historical introductions coupled with most imaginative explanatory etchings enhance readability for the student.'

Irish Medical Journal

'Hooray! Here is a book I can unreservedly recommend. ... we have needed a book like this for some time. It deserves to corner the market.' 


\section{Essential \\ Community Medicine (including relevant social services)}

\section{R. J. Donaldson}

OBE, CStJ, MB, BCh, FFCM, DPH

Royal Free and St. Mary's Hospital Schools of Medicine, Hampstead Health Authority;

Formerly Director of Studies,

Centre for Extension Training in Community Medicine, London School of Hygiene and Tropical Medicine

\section{L.J. Donaldson}

MSc(Anat), MD, FRCS(Ed), MFCM, Regional Medical Officer and Head of Clinical Policy, Northern Regional Health Authority;

Formerly Senior Lecturer in Epidemiology, University of Leicester 
Published in the UK and Europe by

MTP Press Limited

Falcon House

Lancaster, England

British Library Cataloguing in Publication Data

Donaldson, R. J.

Essential community medicine.-(Essential series)

1. Public health 2. Medical care

I. Title II. Donaldson, L. J.

362.1'0425 RA425

ISBN-13: 978-94-011-6251-7 e-ISBN-13: 978-94-011-6251-7

DOI: 10.1007/ 978-94-011-6251-7

Published in the USA by

MTP Press

A division of Kluwer Academic Publishers

101 Philip Drive

Norwell, MA 02061, USA

Library of Congress Cataloging in Publication Data

Donaldson, R. J. (Raymond Joseph)

Essential community medicine.

Bibliography: p.

Includes index.

1. Public health-Great Britain. 2. Medicine, preventive-Great Britain.

3. Community health services-Great Britain. I. Donaldson, L. J. II. Title.

(DNLM: 1. Community medicine. W 84.5 D676E)

RA485.D66 $1982 \quad 362.1^{\prime} 0941 \quad 83-708$

First published 1983

Reprinted with minor changes 1983

Reprinted 1984

Reprinted with updated material 1985

Reprinted with further updating 1987

Reprinted and updated 1988

Copyright (c) 1983 R. J. Donaldson and L. J. Donaldson

Softcover reprint of the hardcover 1st edition 1983

All rights reserved. No part of this publication may be reproduced, stored in a retrieval system, or transmitted in any form or by any means, electronic, mechanical, photocopying, recording or otherwise, without prior permissio from the publishers.

Phototypesetting by Georgia Origination, Liverpool 


\section{Contents}

Acknowledgements vi

Preface vii

1 Health data and their sources 1

2 Patterns of disease 61

3 Origin of diseases and their prevention 113

4 The National Health Service and social $\begin{array}{ll}\text { services } & 165\end{array}$

5 Physically handicapped persons 237

6 Mothers and children 271

7 Mentally disordered people 353

8 Elderly people 423

9 Communicable diseases and parasites 467

10 Environmental health 537

Index $\quad 581$ 


\section{Acknowledgements}

One of the benefits of a long professional career is that I hav made a wide range of contacts in different disciplines. It is a grea pleasure for me to name those who have freely contributed thei specialist knowledge in reading various parts of the text: Ia Alexander, John Ashley, John Ashton, Bill Bate, Michael Bishop Sidney Chave, Philip Clements, John Collins, Cliff Darley, Patric] Hamilton, Deirdre Hine, Jill Moore, Anne Parker, Peter Pharoah Roy Pilsworth, Derek Prinsley, Emer Shelley, Bernard Streeter, Hugl Thomas and Linda Tuckey. They are in no way responsible for an: errors or misinterpretation.

Additionally, I would like to thank the many students in medicin and nursing whose pertinent comments at different stages greatl: helped in the development of this book. I was particularly fortunate if having a cooperative publisher and would especially like to thank Phi Johnstone who exhibited infinite patience throughout the variou stages of the production of the book.

R.J.D 


\section{Preface}

This basic textbook of Community Medicine, which includes descriptions of the related social services, is intended for a wide range of readers who require knowledge and understanding of the essential aspects of the subject. These include undergraduate medical students and qualified doctors who are engaged in postgraduate courses of study or training schemes, particularly those in community medicine and general practice. When writing this book we also had in mind the needs of students of nursing at all levels at a time when an increasing emphasis on the community is being reflected in the content of curricula and the composition of examination papers.

It is our view that this account of community medicine will also be of value to established practitioners - community physicians, community health doctors, senior nurses and health visitors - who wish to consolidate or update their knowledge. The growing involvement of the professions in the management and planning of health services means that many general practitioners, hospital doctors and nurses are being called upon to take a population perspective and to become acquainted with many of the concepts and issues discussed in this book.

In addition, there are those professionals who work closely with medicine and nursing and have a common concern in providing care and promoting prevention - groups such as social workers and health education personnel. For all these reasons we would hope that many groups might read the book and find it useful.

In presenting the material we have drawn on our own practical and teaching experience, as well as the very extensive literature. In so doing we are ever conscious of the debt we owe to our colleagues, both past and present, in shaping and modifying our approach to the subject.

In the first chapter, we have introduced the main steps to be taken in 'diagnosing' the health problems of a population. This is often a field of study, involving as it does a wide range of health data, which students find daunting. In attempting to demystify it we have put special emphasis on providing simple descriptions and definitions of the concepts involved and explaining the origins of the common types 
of routinely available data, as well as giving examples of their uses. An outline of basic statistical methods is also included.

Chapter 2 describes the ways in which the nature and frequency of health problems can vary within different groups of the population, from one time period to another or in different geographical locations. Examining the pattern of disease in populations in this way can provide the starting point for studies investigating the causes of disease or encourage service initiatives. At the end of the chapter a systematic description is given of the main features of several common causes of death in industrialized countries: lung cancer, breast cancer, stomach cancer, ischaemic heart disease, cerebrovascular disease and accidents.

In Chapter 3, we deal with the concept of 'cause' before moving on to introduce the reader to one of the most important and exhilarating aspects of community medicine: prevention. Few would deny the importance of preventive medicine, but it has seldom enjoyed the financial support commensurate with the apparent esteem in which it is held. The main strategies in prevention are introduced and fully described in this chapter: health education, immunization and screening and change in legislation and social policy.

In these first three chapters many of the scientific foundations of community medicine are laid down. Throughout, the reader is made aware of the strengths and limitations of the data, the traps that lie in wait for those drawing hasty or superficial conclusions from them and the practical difficulties involved in pursuing preventive goals.

The modern welfare state is a large and complex structure with diverse origins and traditions. During the last decade social services departments have been created and the National Health Service itself has undergone two major reorganizations in 1974 and 1982. Chapter 4 brings together in one place a description of the present structure, organizational framework and method of functioning of this wide range of services. Health and social services are delivered within a complex legal framework and a very brief account is given of the relevant legislation. In undertaking such a description it is necessary to strike a balance between over-complexity and undue simplicity. Hence, to preserve clarity only the broad issues have been dealt with and are in general terms correct, though it must be accepted that there are inevitably exceptions to some of the statements made.

The measurement and description of health problems, aspects of cause and prevention, service provision and legislation are dealt with in Chapters 5 (Handicapped People), 6 (Mothers and Children), 7 (The Mentally Disordered) and 8 (The Elderly). In describing the services provided for these important groups of the population, we have tried to avoid merely cataloguing them, but have commented, where relevant, on their availability and highlighted innovations and 
deficiencies. Changes as a result of recent legislation such as the Child Care Act 1980, Education Act 1981 and in the law in relation to mental disorder have been taken into account.

Control of communicable diseases can be achieved only by adherence to a set of rules and these are outlined in Chapter 9. The main features of some important infectious conditions occurring in Great Britain are given, including those about which there has recently been some concern, such as the haemorrhagic fevers and hepatitis.

As well as the more traditional aspects of environmental health, we discuss in Chapter 10 the impact of environmental noise, air pollution and radiation in the light of the latest knowledge. The validity of the historical association between housing and health is also re-examined.

Some of the illustrations are reproduced from teaching material and we thank Angela Chorley and Julia Polonski who originally drew them. Government material is reproduced with the permission of the Controller of Her Majesty's Stationery Office.

We would like to record our thanks to Geraldine McNeill for her expert help with the final manuscript and to Lesley Williams for secretarial support at various stages. The generous and cheerful way in which Peter Waters provided his administrative skills was greatly appreciated. We owe a great debt to David Hall for his assistance, not only on statistical matters but also on more general aspects of the subject. We are particularly grateful to Jeannette Coyle for the speedy and accurate way in which she prepared the many drafts.

January 1987: For this reprinting, the opportunity has been taken to update the text with the inclusion of the changes in NHS management following the Griffiths Report, new information on AIDS, a change in Social Security information and updating of the position in relation to child abuse as well as other minor amendments.

R. J. Donaldson

L. J. Donaldson 